\title{
Malibu Lumber Yard Methods
}

\section{Firm Liaison:}

Lauren Hanson

Marketing Manager

ValleyCrest Companies

This case study was produced in 2010 as part of the Landscape Architecture Foundation's Landscape Performance Series pilot. Firms submitted their projects, and LAF staff worked with firm representatives to document the project and its environmental, social, and economic benefits.

To cite:

Landscape Architecture Foundation. "Malibu Lumber Yard Methods." Landscape Performance Series. Landscape Architecture Foundation, 2010. https://doi.org/10.31353/cs1401

The full case study can be found at:

https://landscapeperformance.org/case-study-briefs/malibu-lumber-yard 


\section{Malibu Lumber Yard - Malibu, CA \\ Methodology for Landscape Performance Benefits}

\section{Environmental}

- Manages the first 3/4-in of rainfall using a system of permeable surfaces, gravel beds, and bioswales, which eliminate the need for a conventional drainage system.

The stormwater benefit was derived from the site construction plans and site tour following construction. All non-building surface area on the site is permeable and the site is graded to direct all runoff to two onsite bioswales. These bioretention facilities are designed to treat the first $3 / 4$-in of rainfall, which equates to about the 85 th percentile for 24 -hour storm events. Capture of larger storm events would not result in significant gains in treating water quality because the dirtiest water occurs during the "first flush" of rain. The City of Malibu approved plans without a conventional storm drainage system because it was determined that stormwater would be sufficiently reduced and treated using this system.

- Removes an estimated $80-94 \%$ of Total Suspended Solids (TSS) in stormwater runoff.

According to the Stormwater Sand Filter Sizing and Design, A Unit Operations Approach by Ben R Urbonas, P.E., Chief, Master Planning and South Platte River Programs, Urban Drainage and Flood Control District, Denver, Colorado (https://udfcd.org/wp-content/uploads/uploads/ resources/technical\%20papers/Sand-flt-paper.pdf), sand filters such as the Delaware Sand Filter Bioswales used on the Malibu Lumber Yard site, can filter out an average of $80-94 \%$ of Total Suspended Solids (TSS).

- Treats $100 \%$ of wastewater in an on-site biomembrane reactor water treatment system.

The wastewater treatment benefit was confirmed in the MEP and Civil plans that show restaurant and restroom waste directed to an onsite water treatment unit manufactured by GE Power and Water, which can treat up to 17,000 gallons of water per day as noted on their website: http://www.gewater.com/products/equipment/mf_uf_mbr/mbr.jsp (no longer available)

- Eliminated potable water use for irrigation by using reclaimed water and reduced the amount of water required for irrigation by $66 \%$ through plant selection.

The current landscape maintenance provider, ValleyCrest Landscape Maintenance, confirmed that $100 \%$ of water used to irrigate the landscape is reclaimed water purchased from the Las Virgines Municipal Water District.

The reduction in the amount of irrigation water needed was determined via a series of calculations as recommended in the USGBC New Construction and Rennovation Reference Guide, Version 2.2 under the Water Efficient Landscape LEED credit.

1. A baseline irrigation calculation was determined by evaluating water usage for plant material with average water requirements covering the same surface area as the existing plant material and using the same irrigation system. In this scenario, plant material would require water 3 times per week with an average of 10 minutes of watering per cycle. 
2. The current water usage for irrigation was determined by calculating actual water used for the low and extremely low water-use plant palette used for the site, which is an average of 10 minutes of watering once each week.

The baseline plant palette would require 305,214 gallons of water per year at the cost of $\$ 498 /$ year. The low water-use palette installed at Malibu Lumber Yard requires 101,735 gallons of water per year at the cost of $\$ 166 /$ year. Chart A below depicts water use calculations for the baseline plant palette and Chart B shows calculations for the current low water use palette.

Chart A - Baseline Plant Palette

\begin{tabular}{|r|r|l|r|l|r|l|r|r|r|r|}
\hline Station & Su & M & Tu & W & Th & F & S & Total & GPM & Total Gal. \\
\hline 1 & & 10 & & 10 & & 10 & & 30 & 3.20 & 96 \\
\hline 2 & & 10 & & 10 & & 10 & & 30 & 5.20 & 156 \\
\hline 3 & & 30 & & 30 & & 30 & & 90 & 1.00 & 90 \\
\hline 4 & & 30 & & 30 & & 30 & & 90 & 1.00 & 90 \\
\hline 5 & & 10 & & 10 & & 10 & & 30 & 24.00 & 720 \\
\hline 6 & & 10 & & 10 & & 10 & & 30 & 8.40 & 252 \\
\hline 7 & & 10 & & 10 & & 10 & & 30 & 7.20 & 216 \\
\hline 8 & & 10 & & 10 & & 10 & & 30 & 18.00 & 540 \\
\hline 9 & & 10 & & 10 & & 10 & & 30 & 2.40 & 72 \\
\hline 10 & & 10 & & 10 & & 10 & & 30 & 8.00 & 240 \\
\hline 11 & & 10 & & 10 & & 10 & & 30 & 2.80 & 84 \\
\hline 12 & & 10 & & 10 & & 10 & & 30 & 6.00 & 180 \\
\hline 13 & & 10 & & 10 & & 10 & & 30 & 24.00 & 720 \\
\hline 14 & & 10 & & 10 & & 10 & & 30 & 6.00 & 180 \\
\hline 15 & & 10 & & 10 & & 10 & & 30 & 9.71 & 291.3 \\
\hline 16 & & 10 & & 10 & & 10 & & 30 & 36.00 & 1080 \\
\hline 17 & & 10 & & 10 & & 10 & & 30 & 22.74 & 682.2 \\
\hline 18 & & 30 & & 30 & & 30 & & 90 & 1.00 & 90 \\
\hline 19 & & 30 & & 30 & & 30 & & 90 & 1.00 & 90 \\
\hline
\end{tabular}

Total Usage in Gallons per Week

$5,869.50$

Total Usage in Gallons per Year Total Usage in HCF Las Virgenes MWD Rate $305,214.00$ 408.04 1.22 Total Cost 497.81

Chart B - Low Water-Use Plant Palette

\begin{tabular}{|c|r|l|l|l|l|l|r|r|r|r|}
\hline Station & Su & M & Tu & W & Th & F & S & Total & GPM & Total Gal. \\
\hline 1 & & 10 & & & & & & 10 & 3.20 & 32 \\
\hline 2 & & 10 & & & & & & 10 & 5.20 & 52 \\
\hline 3 & & 30 & & & & & & 30 & 1.00 & 30 \\
\hline 4 & & 30 & & & & & & 30 & 1.00 & 30 \\
\hline 5 & & 10 & & & & & 10 & 24.00 & 240 \\
\hline 6 & & 10 & & & & & & 10 & 8.40 & 84 \\
\hline 7 & & 10 & & & & & & 10 & 7.20 & 72 \\
\hline 8 & & 10 & & & & & & 10 & 18.00 & 180 \\
\hline 9 & & 10 & & & & & & 10 & 2.40 & 24 \\
\hline
\end{tabular}




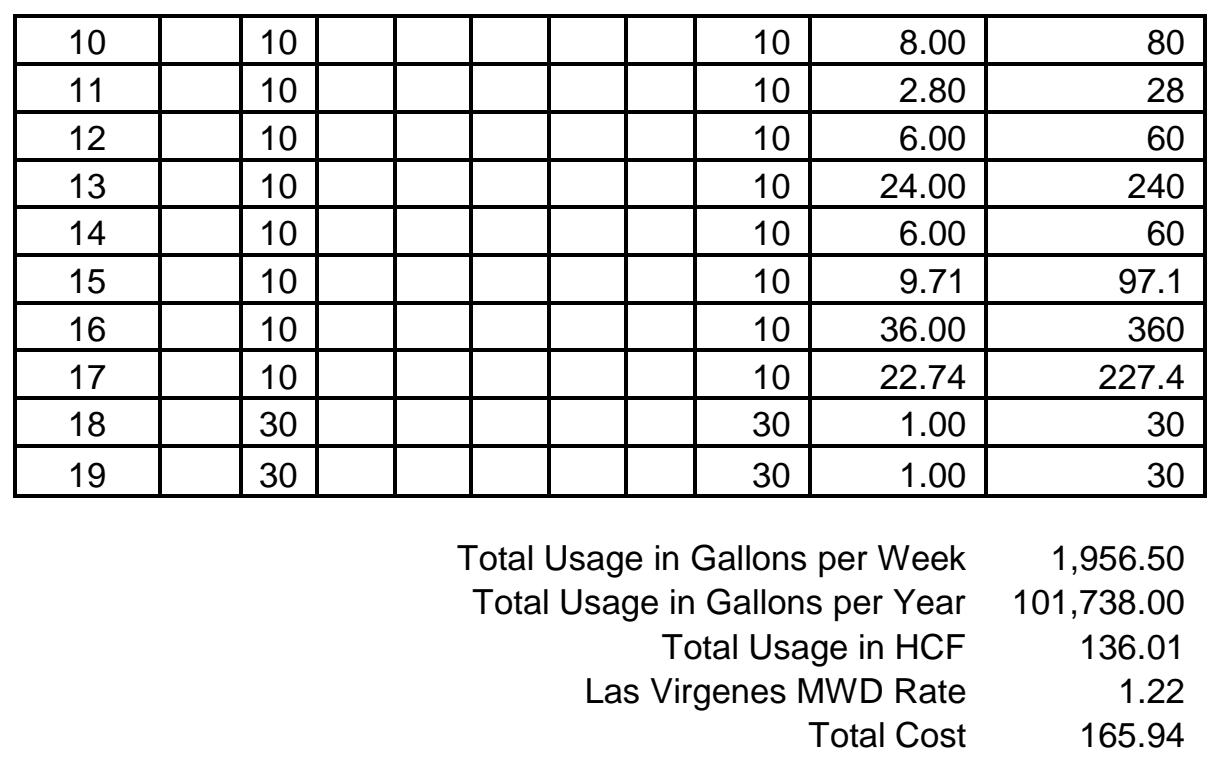

- Contributes to a reduction in the urban heat island effect by replacing $70 \%$ of the existing asphalt on the site with concrete permeable pavers, which have 7 times the reflectance. 19 trees also contribute to this effort by providing shade.

Per the USGBC New Construction and Rennovation Reference Guide, Version 2.2 under the Heat Island Effect LEED credit, asphalt has a very low SRI of zero and reflectance of 0.05 , whereas concrete (in the form of permeable pavers), the replacement material for $70 \%$ of the site has a SRI of 35 and reflectance of 0.35 . With the additional enhancement of shade from 19 additional trees per site construction plans, the new design allowed for a significant increase in solar reflectivity and in turn a reduction in heat island effect.

\section{Economic}

- Commands rents that are $5 \%$ higher on average than those in surrounding retail centers.

Figure from CB Richard Ellis, the property management company for Malibu Lumber Yard. 